\title{
Expectations in engineering programs - between social construction and internalized experience
}

\author{
Mr. Hindolo Michael Kamanda, University of Georgia \\ Undergraduate researcher at the University of Georgia

\section{Mr. Davis George Anderson Wilson, University of Georgia} \\ Undergraduate researcher at the University of Georgia
}

\section{Dr. Joachim Walther, University of Georgia}

Dr. Joachim Walther is a Professor of engineering education research at the University of Georgia and the Founding Director of the Engineering Education Transformations Institute (EETI) in the College of Engineering. The Engineering Education Transformations Institute at UGA is an innovative approach that fuses high quality engineering education research with systematic educational innovation to transform the educational practices and cultures of engineering. Dr. Walther's research group, the Collaborative Lounge for Understanding Society and Technology through Educational Research (CLUSTER), is a dynamic interdisciplinary team that brings together professors, graduate, and undergraduate students from engineering, art, educational psychology, and social work in the context of fundamental educational research. Dr. Walther's research program spans interpretive research methodologies in engineering education, the professional formation of engineers, the role of empathy and reflection in engineering learning, and student development in interdisciplinary and interprofessional spaces.

\section{Dr. Nicola W. Sochacka, University of Georgia}

Dr. Nicola Sochacka is the Associate Director for Research Initiation and Enablement in the Engineering Education Transformations Institute (EETI) in the College of Engineering at UGA. Supported by over $1.5 \mathrm{M}$ in funding, Dr. Sochacka's research interests include systems thinking, diversity, STEAM (STEM + Art) education, and the role of empathy in engineering education and practice. Her work has been recognized through multiple best paper awards and keynote presentations at international and national conferences and workshops.

\section{Dr. Stephen Secules, Florida International University}

Dr. Stephen Secules is an Assistant Professor Engineering and Computing Education at Florida International University. He has a prior academic and professional background in engineering, having worked professionally as an acoustical engineer. He has taught a number of courses on engineering and education, including courses on engineering design, systems in society, and learning theories. Stephen's research interests include equity, culture, and the sociocultural dimensions of engineering education.

\section{Dr. James L. Huff, Harding University}

James Huff is an assistant professor of engineering at Harding University, where he primarily teaches human-centered design in engineering. His research interests are aligned with how engineering students develop in their career identity while also developing as whole persons. James received his Ph.D. in engineering education and his M.S. in electrical and computer engineering, both from Purdue University. He received his bachelor's in computer engineering at Harding University. 


\title{
Expectations in engineering programs - between social construction and internalized experience
}

\begin{abstract}
:
Prior research established that expectations play a significant role in students' educational experiences. Academic and non-academic expectations can contribute to students' stress and anxiety, and have been shown to impact achievement and retention. This study uses ethnographic methods to investigate how expectations are socially constructed in engineering programs and how students' come to internalize these expectations. Data was collected in ten focus groups with a total of 38 participants at two universities with different institutional characteristics. The qualitative analysis drew on constant comparative methods and proceeded from topic coding of sources of expectations to interpretive coding of mechanisms in which students internalized experiences. More specifically, sources of expectations were identified as academics, superiors, peers, extra-curricular, and from outside the major. The rich account of students livedexperiences show a complex interplay of expectations from multiple sources. The mechanisms of compounding, conflicting, and triangulating expectations show that the interactions of expectations can amplify their emotional impacts on students. The results indicate that students judge their own performance or belonging in engineering relative to the systemic functioning of expectations. For educators, this insight has profound implications on how we communicate performance standards without inadvertently reinforcing social performance expectations that can contribute to problematic cultural features of engineering learning environments.
\end{abstract}

\section{Introduction}

In the broader discourse around student diversity and retention [1-4], prior studies examine students' experiences around academic and non-academic pressures [5, 6] and stress $[7,8]$. These studies recognize the range and extent of expectations on engineering students as increasingly relevant for student achievement $[9,10]$ and retention [11], with a particular focus on the impacts on underrepresented groups in engineering [12,13]. A related strand of the engineering education discourse examines cultural influences and pressures on students' experiences and their professional socialization within the overall context of engineering programs $[14,15]$.

In examining the individual impacts of some of these pressures on students, emerging work has begun to explore students' experiences of shame [16-18]. More specifically, Huff, et al. [17] conceptualize "professional shame to be a painful emotional state that occurs when one perceives themselves to have failed to meet socially constructed expectations or standards that are relevant to their identity in a professional domain".

The study reported here is the first part of a larger inquiry of shame experiences in engineering programs and how these may play a role in the professional socialization of our students. More specifically, an understanding of shame experiences and student responses can shed light on the collective social construction of expectations and social norms in engineering. To lay the 
foundation for the study of shame in engineering, this inquiry uses focus groups with an ethnographic orientation towards the broader cultural context to explore the social construction of expectations that may constitute sources of shame for students. While stated academic performance standards play a role in students' experience, we defined expectations more broadly as the implicitly assumed or explicitly stated markers of success and belonging in an engineering program. The qualitative analysis of the focus group data uncovered categories for sources of expectations and distinct patterns in the ways in which students' come to internalize these expectations. These findings provide the foundation for examining students' shame responses to not meeting those expectations, a consideration that is beyond the scope of this article and the focus of future work.

\section{Literature Review: Expectations and Their Impacts on Students}

A growing strand of scholarly dialogue in higher education explores connections between students' emotional experiences with pressures and stress, and student achievement and retention. Relevant studies identify general academic pressures including parental expectations, grades, test taking, time pressures, and future plans [19] as well as those unique to engineering students, such as family pressure to study the major [20]. Some studies specifically focus on student stress [21, 22] and impacts on students' mental health [19, 23].

Students often experience anxiety due to the stress of these expectations as well as fear of failure to fulfill them [24]. In the context of a study of psychological distress in college students, Bottesi, et al. [25] found that anxiety and intolerance of uncertainty can lead to negative beliefs and outcomes expectations that can affect student performance [see also: 26]. A study of engineering students [20] found that low stress levels and positive outcome expectations increased students' self-efficacy, a factor that, in turn, significantly predicted academic achievement. Related studies identified stress as a key predictor for low student engagement and persistence [27] as even students with high ability in science often leave STEM majors due to significant accompanying pressure and accompanying physical and psychological distress [28, 29].

Minority students can be disproportionately impacted by such emotional experiences due to their socio-demographic characteristics [30-32] in conjunction with their academic environments [10, 33]. As such, minority students may be more vulnerable to negative emotional experiences such as loneliness [34, 35] and low self-esteem [33], as well as negative outcomes such as decreased academic achievement [36] and attrition [11], although these outcomes are certainly not unique to minorities. Negative emotions can also diminish student motivation which may impair learning strategies and student outcome [37].

The complex interplay of emotions and behaviors is especially applicable to engineering, a field in which students' self-perception, behaviors and performances are often shaped by the context of their academic environments [38]. Prior research identifies a range of emotional experiences as vital in both social [34] and academic [22,36] contexts. More specifically, students appear to have perceptions about themselves and their environments [39] which are subsequently informed by their experiences in those environments $[40,41]$. The environments are in turn guided by a set of academic and non-academic expectations $[5,6,42]$ that inform the social and professional formation of students [43]. Some of these broader cultural dimensions of expectations for 
students in engineering, have been explored in studies of student experiences [44] and have more recently received attention in studies of larger cultural features [45-47] disciplinary narratives , or metaphors [48] that describe and, in turn shape, the field.

Building on this prior work, the present study explores students' lived experiences of expectations in the larger cultural and disciplinary context of engineering.

\section{Research Question}

Aligned with the above focus, the inquiry addresses the following two research questions:

1. What are sources of expectations for engineering students that emerge from their overall educational experience?

2. How are these expectations experienced and internalized by students?

\section{Theoretical Framework}

Set in the context of the broader consideration of shame experiences and responses, this study examines the sources that inform students' understanding of expectations and their subjective perception of not meeting those expectations or social norms. Figure 1 illustrates the theoretical framework [16] that informed the focus and scope of this study and informed the research design. More specifically, the model shows both how socially constructed expectations and standards of behavior are interpreted by the individual student. A subjective negative evaluation of the self in relation to perceived expectations can lead to individual students' experiences of shame $[16,17]$. Students' responses to shame can, in turn, contribute to the social construction of expectations in the disciplinary and cultural context.

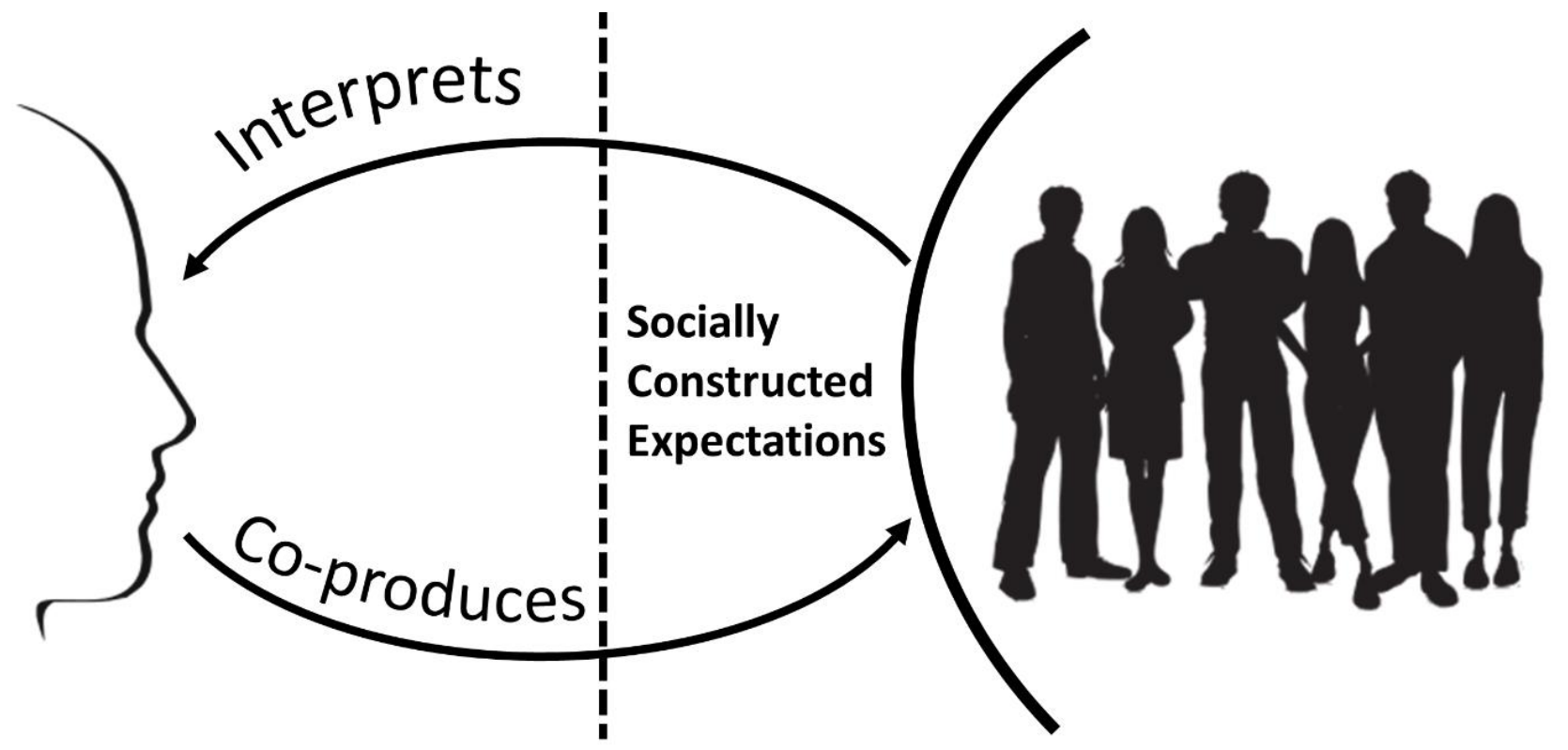

Figure 1: Conceptual model illustrating the social construction and internalization of expecations 
The focus of this study was to examine the sources of expectations in the educational context and explore the ways in which students collectively construct both implicit and explicit expectations for what is means to be, and to succeed as an engineering student. The framing through shame directs the empirical focus on students' perceptions of not meeting those collectively constructed expectations and social norms. It is important to note that this perception of not meeting expectations is highly subjective and does not necessarily relate to a students' objective performance relative to explicit standards.

\section{Research Design}

Informed by the theoretical framing around the collective, social construction of expectations, the data collection was informed by an ethnographic approach $[49,50]$ in student focus groups $[51,52]$. More specifically, the data gathering as well as the subsequent qualitative analysis purposefully attended to the cultural context in which students' expectations were situated and that profoundly impacted their lived experiences of those expectations. A total of 10 semistructured focus groups were conducted with 38 students at two different institutions (See details below). The focus groups were recorded and transcribed for subsequent analysis in the qualitative analysis software NVivo [53].

\section{Methodology and Methods}

The focus groups explored individual students' lived experiences and perceptions around expectations with a view to understanding the cultural context in which their perceptions of and reactions to those expectations were situated. More specifically, the protocol elicited individuals' experiences around expectations and the facilitator followed up with questions that established the details and context of individual experiences. The facilitator initiated the discussion with a question about the context of expectations in the engineering program. To ground the discussion not in students' perceptions, but in their lived experiences the follow-up questions by the facilitator prompted students to recall specific incidents or times when they experienced not meeting explicit or perceived expectations. The focus on instances where students subjectively perceived not meeting expectations also aligns with the theoretical framework of shame that guided the design of the larger study.

The focus group format was then conducive to uncovering the cultural dimensions as the individual's accounts took place in a safe, but nevertheless public forum. In the data, we observed that individual students expressed their individual experiences in terms that were appropriate to the group setting and that the discussion often provided a microcosm of the collective construction of expectations. For example, individual accounts would often hint at profoundly emotional internal experiences but students would express those experiences and their own reactions in socially acceptable terms that often corresponded to cultural norms around rigor and hard work in engineering.

The focus group discussions with 2-5 students took about 60-90 minutes and were facilitated by a co-researcher (6th author) who was not involved in the teaching of the participants' courses. The discussion followed a semi-structured protocol with prompts to elicit individual accounts of expectations and follow-up questions that guided students to elaborate on the details and context of those accounts. As a whole, the focus groups started with a broad exploration of expectations 
with a shared discussion that prompted further recall of experiences. Subsequent questions explored particular areas of expectations that had emerged as significant in the present or in prior focus groups.

The focus groups were audio recorded and professionally transcribed with the members of the research team checking the transcripts for accuracy and de-identifying both speakers and individuals named in the discussion. The deidentified data was used for analysis and data presented in this manuscript use consistent pseudonyms for participants.

\section{Research Sites}

Data was collected at two institutions, a large research intensive (RU) and a small, teachingfocused, and faith-based university (TU).

The research-intensive university offers a comprehensive engineering program with about 2200 students in eight degree programs. The academic environment is characterized by a significant growth in student numbers and resulted in the introduction of a performance-based enrollment management system. Students apply in their third semester to the major and the selection is informed by grades in core engineering courses and the evaluation of a personal statement. In addition to the demands on students that all engineering programs share, this application process constitutes additional performance pressures for the students. At the same time, the program has a legacy and current culture of collaboration between students, a strong cohort sense and identification with the major and institution.

The small, teaching-focused university offers five engineering degree programs which enroll approximately 250 students. Although the curricular plan of the engineering programs is, in many ways, similar to the programs at the research-intensive university, the institutional culture at this university is characterized by a holistic focus on the development of whole persons, particularly in relation to faith and spirituality. Students commonly declare their particular engineering major upon admission into the university, and there are no program-specific admission requirements. While students in the engineering program are navigating common expectations of achieving high performance in relation to their coursework, they also actively engage the question of where they should prioritize their engineering activities in relation to who they are as whole persons. Furthermore, the students often have certain professors for multiple courses, which facilitates a salient interpersonal relationship between professors and students at the teaching-focused university.

The diversity of institutional contexts allows the research to uncover robust common patterns and, at the same time, explore the richness of the ways in which these patterns manifest in the local context [Theoretical Validation in 54].

\section{Participants and demographic information}

Across the two research sites, ten focus groups were conducted with a total of 38 participants. Table 1 below provides an overview of the focus groups in terms of institutional context, participants, and demographic information. 
Table 1: Participant demographic data

\begin{tabular}{|c|c|c|c|c|c|}
\hline$\#$ & Institution & Gender & $\begin{array}{l}\text { Racial Self- } \\
\text { identification }\end{array}$ & Majors & Year/ level \\
\hline 1 & \multirow{5}{*}{ RU } & 4 Men & White & Mechanical & $\begin{array}{l}1 \text { freshman, } 2 \\
\text { sophomores, } 1 \\
\text { junior }\end{array}$ \\
\hline 2 & & 4 Men & White & Mechanical & $\begin{array}{l}2 \text { sophomores, } 1 \\
\text { junior, } 1 \text { senior }\end{array}$ \\
\hline 3 & & 2 Women & $\begin{array}{l}\text { African American, } \\
\text { White }\end{array}$ & Civil, Mechanical & $\begin{array}{l}1 \text { freshman, } 1 \\
\text { senior }\end{array}$ \\
\hline 4 & & 4 Women & $\begin{array}{l}\text { Asian, Middle } \\
\text { Eastern, 2 White }\end{array}$ & $\begin{array}{l}\text { Biological, Computer } \\
\text { Systems, Mechanical }\end{array}$ & $\begin{array}{l}\text { 1 sophomore, } 2 \\
\text { juniors, } 2 \text { seniors }\end{array}$ \\
\hline 5 & & 5 Women & $\begin{array}{l}1 \text { African American, } \\
2 \text { Asian, } 2 \text { White }\end{array}$ & $\begin{array}{l}\text { Biological, Computer, } \\
\text { Mechanical }\end{array}$ & $\begin{array}{l}1 \text { freshman, } 1 \\
\text { sophomore, } 3 \\
\text { seniors }\end{array}$ \\
\hline 6 & \multirow{5}{*}{$\mathrm{TU}$} & 3 Women & 2 Hispanic, 1 White & Biological & $\begin{array}{l}1 \text { sophomore, } 2 \\
\text { junior }\end{array}$ \\
\hline 7 & & 4 Men & White & $\begin{array}{l}\text { Biomedical, } \\
\text { Electrical, } \\
\text { Mechanical }\end{array}$ & 2 junior, 2 senior \\
\hline 8 & & 5 Men & White & $\begin{array}{l}\text { Computer, Electrical, } \\
\text { Mechanical }\end{array}$ & 5 sophomore \\
\hline 9 & & $\begin{array}{l}2 \text { Women, } \\
3 \text { Men }\end{array}$ & $\begin{array}{l}2 \text { Hispanic, } 3 \text { White } \\
(1 \text { female, } 2 \text { male })\end{array}$ & $\begin{array}{l}\text { Biomedical, } \\
\text { Electrical, } \\
\text { Mechanical }\end{array}$ & $\begin{array}{l}1 \text { sophomore, } 4 \\
\text { junior }\end{array}$ \\
\hline 10 & & 5 Men & 1 Hispanic, 4 White & Mechanical & 5 Junior \\
\hline
\end{tabular}

The sampling strategy and participant recruitment aimed for mostly homogeneous groups in terms of majority and minority participants. We defined minority and majority status in terms of race and gender. This research design feature [Procedural validation in 54] was intended to increase opportunities for participants to co-construct authentic accounts of their experiences (Communicative Validation) in light of the potentially sensitive and emotional qualities of their experiences. More specifically, we observed that in minority focus groups, students tended to be more comfortable revealing personally challenging experiences and connecting with other participants' accounts. Similarly, the discussion in groups with majority participants tended to emphasize emotional content less and focus more on accounts of individual perseverance or framed individual experience in terms of generalized advice for other students. This sampling strategy did not aim for representation of particular perspectives and we recognize the intersectionality of the identity facets of our participants [55]. Rather, the composition of the focus groups aimed to maximize variation in perspectives and experiences while creating environments where those perspectives could be shared. Accordingly, the analysis does not aim to establish systematic differences between the participant groups, a focus that is beyond the scope of this study and the subject of future work. 


\section{Data Analysis and Research Quality}

The focus groups were digitally recorded and transcribed. The research team checked the transcripts and de-identified both speakers and individuals mentioned in students' accounts. The de-identified transcripts were imported and organized in NVivo 8 for further analysis.

The iterative analysis progressed from topic coding [56] of accounts in participants' experiencenear terms [57] to interpretive coding that established abstract patterns across the topic codes. More specifically, the first level captured how students described sources of their expectations in their own terms, e.g. "student clubs". In the next step these codes were clustered and described at a more abstract level, e.g. extracurricular influences, a higher-level category that also included perceived student expectations around "internships".

The data analysis was conducted by three undergraduate researchers (author 1, 3 and 4) in collaboration with an experienced engineering education researcher (author 2). The team engaged in multiple iterations with systematic processes of negotiating the emerging interpretations in the whole research team based on review and discussion of primary data [Communicative Validation in 54]. This shared meaning was supported by systematic documentation in coding reports for each category that followed a common structure and captured the emerging definitions for each code, critically reflective writing about the formation of the category, and notes about connections to other categories (Process Reliability).

Alongside the interpretive coding the team engaged in shared model building activities. As functional relationships between categories seemed to emerge, we attempted to capture these in multiple iterations of visual models. Where the connections between topic categories provided a sense of additional explanation or resonance, the data set was re-coded for those functional patterns. For example, the findings that capture the ways in which students internalize expectations were the product of this systematic process of model building and re-coding.

\section{Findings}

The following provides an overview of the sources of expectations described by the participants. Based on these categories, the second part of the findings provides a sense of the ways in which these expectations dynamically interact and are internalized by students. Figure 2 provides a contextual model to illustrate the analytic categories and their functional relationships.

\section{Sources of Expectations}

A critical component of the model of shame in engineering is the set of expectations through which students internalize and interpret socially constructed standards. In our analysis, 5 major sources emerged that capture an intricate web of expectations, namely: academics, engineering superiors, engineering peers, extracurricular activities, and entities outside the engineering major.

Invariably, academics was a principal expectation source for many students due to its directly evaluative nature and significant implications. For our purposes, academic sources of expectations were defined as all activities, assessments, and requirements which serve as measures of academic competence of engineering students. An example of such expectations is a course exam which evaluates students' knowledge and understanding of the relevant course material. 


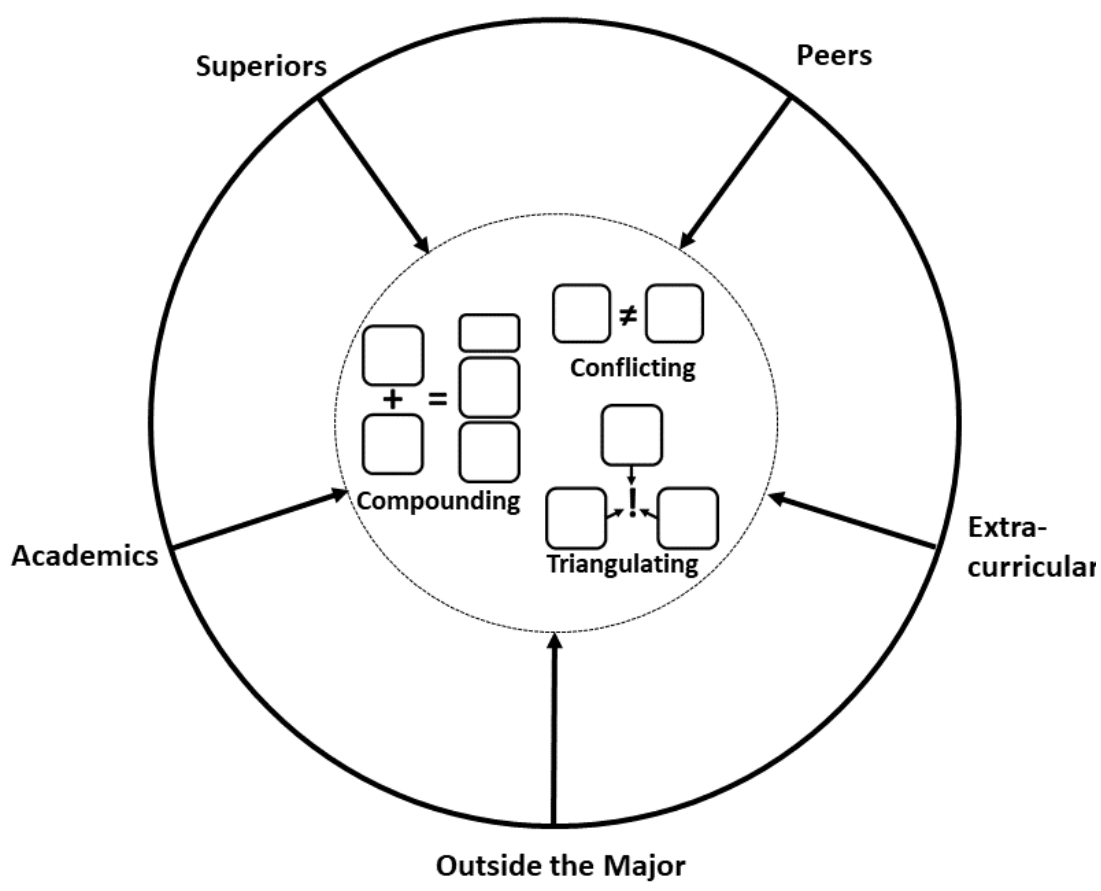

Figure 2: Contextual model for sources of expectations and ways of internalizing expectations

The following statements from Tehzlyn, a second-year mechanical engineering major, illustrate students' academic responsibilities, specifically managing their own learning and preparing for academic evaluations.

"Yeah, I think that what you're saying, they can't cover everything in a class, and so it's expected that we're going to have to do a lot of self-teaching and selflearning at home, and especially with classes that have pop-quizzes, and so you know, you'll have to really be on top of things, [...], so keeping up with that and balancing those classes -- the material of the classes weekly, yeah" [Tehzlyn, Focus Group \#4 , 00:07:56]

The student describes a clear expectation to independently master course material and to demonstrate mastery by performing well on quizzes. Across the data, assessments were a central theme of this category, particularly in the context of stress. Grades serve as a straightforward, quantitative measure which provides clarity about academic requirements, an element unique to this expectation source. However, that clarity is tempered by the stress of the academic expectations themselves, as well as the potential implications of failure to fulfill them.

Besides academics, expectations can also come from engineering superiors, who were defined as entities within the engineering major with influence to directly and professionally influence a students' grades, learning environment, career-related decisions and other engineering experiences. These entities range from individuals such as professors to small organizations such as the student advising center.

For example, if an instructor unknowingly creates a hostile learning environment with rigid expectations and methods, the learning experience can become extremely stressful, especially 
given the instructor's position of power in that context. The following exchange describes such an environment and depicts students' experiences with stress as a result of harsh learning conditions. Jackson is a senior mechanical engineering major, while John is a second-year mechanical engineering major. They articulate similarly negative experiences with the same professor, despite taking his course in different semesters.

"JOHN: Ifeel like he does that just to teach everyone a lesson (laughs), to wake up early. So that's kind of just the kind of guy he is. He assigns homework, and then doesn't ever take it up, and gives you pop quizzes that are based off the homework. So the only way of making sure you do your homework is he gives you pop quizzes, which are a significant portion of your grade.

JACKSON: He's a very traditional engineering guy [...] You know, you shouldn't have any social life. You should be going home and studying.

$[\ldots]$

JOHN: The whole way the class is run is like [...] He'll -- If you don't know the answer to a question he'll harp on you for a good five minutes.

JACKSON: Yeah. It was a stressful class. (laughs)

JOHN: It is really stressful.” [Focus Group \#1, 00:06:00]

Here we see students admitting to experiencing stress due to the classroom conditions created by a professor. While the professor's expectations are not inherently harsh, students perceive an attempt to send a message ("teach everyone a lesson") about how developing engineers should conduct their lives even outside the classroom. Though his goal is to encourage learning, his approach stifles the learning process and introduces stress to an extent that it may appear to students that he deliberately attempts to cause distress. The consistency of the effects of his philosophy, illustrated by statements such as, "the whole way the class is run", "it was a stressful class", and "it is really stressful", suggest that this salient experience is shared by a significant portion of his past and present students, as well as students of professors with similar approaches. Therefore, a vital element of expectations from superiors is the way these expectations are presented and may imply social or cultural norms to students.

On a more horizontal level, engineering peers can serve as a prominent source of expectations for engineering students, due to proximity and shared norms and behaviors. Engineering peers were defined as other engineering students with experiences and challenges comparable to those of the student.

A common example of such expectations is a female student who is pressured to display predominantly masculine behaviors such as competitiveness and assertiveness, even when such behaviors are unlikely to benefit them. The next two quotes work in tandem to illustrate this point, with the first quote from Vivian (junior computer engineering student) recounting some of the negative peer influences, and the second quote from Kia (first-year mechanical engineering student) describing a reactive behavior associated with such treatment. 
"The guys in engineering make me really mad a lot of times, because they're -(sighs) They look down on you because you're a girl, especially in one that's almost all guys. They're like oh, you're doing this, okay. I'm like okay, yeah, I'm actually trying." [Vivian, Focus Group \#6, 01:06:00]

“Because -- I don't know, it just makes me feel like I'm a competitive person, but not oh, I'm trying to be better than everybody else, but I -- I don't also -- I don't like to feel lesser or not as capable, or even people to assume that not -incapabilities of me, so I'm less likely to raise my hand and ask for help, so I don't know. "[Kia, Focus Group \#3, 00:40:00]

In recounting a snide show of approval from a male student, Vivian presents a common theme in the data, that female students receive occasional but powerful comments which question their competence. Her emphatic account emphasized with a "sigh" highlights the frequency of the experience and the distress it brings. Chiefly, women perceive these comments as disrespectful and sexist, and suffer threats to self-perception resembling the one Kia describes. Thus, Vivian's experience illustrates how gender-related peer expectations are constructed, while Kia explains how they are perceived from a minority perspective. While experiences of underrepresented students powerfully illustrate the role of peer influences, similar constructions and perceptions of such expectations were frequently described by other participants, indicating that this example of peer-related expectations may be a haunting reality for many students.

Extracurricular activities were also identified as a vital source of expectations for students, especially professionally oriented ones such as internships and student organizations. They were defined as activities with no direct academic intent, but are managed alongside academics in order to enhance professional development.

The expectation to obtain an internship in order to solidify one's engineering self is a common example which can severely impact a student's self-perception if not met. First-year mechanical engineering student Kassidy expresses the general awareness of this expectation in the department, as well as the personal stress she experiences as a result of it.

"Right now is the time for applying for internships. So all my friends are applying for different internships and I'm not, because I don't know where to find one, and I have looked and most of the ones that are interesting to me, they require like experience that I don't have at the moment, so I'm just putting that off for now, but I feel pressure” [Kassidy, Focus Group \#5, 00:15:00]

Principally, Kassidy discusses an inability to obtain an internship due to lacking both information and experience ("I don't know where to find one", "they require experience that I don't have"). As a result, she has postponed her internship search, likely in order to gain additional experience. However, she clearly experiences pressure, because "right now is the time for applying for internships". Here we see an element of time associated with these expectations which introduces additional pressure on students. Even though a freshman student herself, Kassidy buys into a widespread sense of urgency among engineering students, especially juniors, who often believe that they cannot fit the expected level of extracurricular activities into their overall studies. 
Equally powerful for contributing engineering expectations are entities completely outside of engineering. This category is broadly defined as individuals or organizations who express or have expressed judgments about a student's status as an engineer or what it takes to be an engineer. As a prevalent theme, these individuals tend to be family members who exert undeniable influence on students' self-perception.

For example, parents' high expectations can significantly increase the students' stress levels, particularly when they suggest that high achievement is a student's innate ability. In the following statements fifth-year civil engineering student Jade narrates her experience with her parents who believe that her mediocre performances were entirely due to a lack of effort on her part.

"My parents were really disappointed (laughs) with my grades, -- [...] Because they expected high grades out of me, and oh, well, you're not studying enough, or you know, they just thought I wasn't trying or that I was you know, maybe socializing too much and not studying enough, so -- I think that is definitely an expectation to be -- to do well in your classes and -- as an engineer. [Jade, Focus Group \#3, 00:20:00]

Jade discusses the experience of a typical engineering student, who probably excelled in earlier stages of her education, but does not achieve the same level of grades in her engineering studies. Her parents believe that she has the innate ability to continue her excellence in the engineering program, so the disappointment is not just with the performance, but the student herself. In their view, the only reason why Jade would not be a high achiever is due to a lack of effort. Jade's account serves as an effective lens for observing the distress caused by high parental expectations. There is also the general perception that engineers simply excel ("as an engineer"), which exists beyond the program and introduces an extremely potent layer of pressure, especially for students who once excelled in school. In this way, entities outside of the major can have powerful input on the construction of expectations within engineering.

\section{Ways of internalizing expectations}

Each of the above sources of expectation can have varying levels of impact depending on the priority and context of the source as well as the students' own values and prior experiences. The next level of findings describes three mechanisms through which sources interact to impact a student's perception of expectations as well as their self-perception. Expectations are not specific to individual mechanisms, but the same expectation can be internalized differently depending on the student and the context. More specifically, compounding, conflicting, and triangulating of expectations describe dynamic ways in which expectations interact with often amplified impacts on the emotional experiences of students.

\section{Compounding Expectations}

Compounding expectations are defined as expectations from multiple sources that encourage a similar set of behaviors. Students are generally concerned about meeting expectations from various sources and may prioritize those influences differently. Although each source contributes distinct expectations, they can combine to construct a system of expectations about engineering 
identity and performance. This coherence is largely due to a silent dialogue among the sources, as each source essentially presents its own interpretation of the engineering field. Each resulting expectation contributes appreciable levels of pressure, so compounded expectations are likely to induce substantial stress as students feel compelled to meet every expectation in order to maximize their chances of success. Due to the demanding nature of the engineering major, however, fulfilling compounded expectations often proves challenging as students struggle to balance various responsibilities in an attempt to establish a holistic engineering identity.

As an example, the following quote demonstrates the lived experience of Kia, a first-year mechanical engineering student. While success as a student is evidently central to her developing engineering identity, fulfilling other expectations contributes critically to her overall sense of competence as a developing engineer. While endeavoring to become a well-rounded engineering student, she experiences severe stress associated with simultaneously maintaining all aspects of her engineering identity.

"I'm not just a student, even though I am a student first, I'm not just a student. I work as well, and I'm in three or four different clubs, so I have to show if I'm thinking, okay, I want a job or an internship, I have to be a well-rounded person who can handle these kinds of stresses of having a job and getting your school work done, and being a part of clubs, and showing leadership, and this, and that, and [...] I just need more hours in the day." [Kia, Focus Group \#3, 00:50:00]

Kia's statements suggest that she is overwhelmed by the compounding expectations not just because they each require time and effort, but because the resulting system of expectations appears greater than the sum of its parts. In other words, instead of attending simply to a series of responsibilities, she attends to one major responsibility, which is to track and satisfy all the individual requirements necessary to become well-rounded. This system of expectations induces additional stress partly because it seems to create an interminable process of identifying and accomplishing a collection of goals, without even a clear idea of success. Profoundly, she implies that a primary objective might be to simply demonstrate an ability to handle various kinds of stresses ("I have to be like a well-rounded person who can handle these kinds of stresses"), because in her mind that constitutes well-roundedness as an engineering student. This belief that experiencing high amounts of stress correlates to one's legitimacy as an engineering student emerges throughout the data, as does the frustration ("I just need more hours in the day") which accompanies an inability to effectively and consistently satisfy the system of expectations student experience. Compounding expectations produce such powerful reactions because they imply that a deficiency in any expectation category is a deficiency in meeting the overall structure of expectations, which indicates deficiency as an engineering student, regardless of other accomplishments. Thus, this mechanism represents a fundamental interaction of external expectations to construct a system of expectations focused on stress and activity without an objective much more substantial than simply showing it.

\section{Conflicting Expectations}

Though vital, compounding expectations represent just one strand of the expectation interactions that have significant implications for engineering students' experiences. A related mechanism is conflicting expectations which are defined as expectations from multiple sources that encourage 
opposing/conflicting norms and behaviors. The distinctive characteristic of this mechanism is that it introduces an additional layer of uncertainty due to contradictory expectations. Thus, conflicting expectations can produce a powerful dissonance as they lead students to wonder what defines a successful engineering student, and the relevance of each perceived expectation for achieving this status. This dissonance exists because the expectations require students to develop competing facets of their engineering identity, so that efforts to meet one expectation decrease their ability to fulfill the other. With expectations derived from multiple external sources, students are frequently compelled to favor one aspect of their identity at the expense of another trait, behavior, or skill.

The mechanism of conflicting expectations can pull students in several opposing directions and is perhaps most evident if observed with two starkly contrasting expectations. The following statements are from Dale, a junior mechanical engineer at the faith-based institution, whose personal growth is seemingly hindered by his academic obligations. He expresses difficulty fulfilling both expectations due to the competition that exists between them.

"Cayson and I are -- or have tried to be involved in our clubs, holding offices and positions that require us to do things outside of the engineering department, and that's been kind of hard to do with all the time that we spend in the engineering department building doing homework. Then [University] being a Christian university expects us to grow as Christians and to get ourselves in the community and do different things which are very good things, attend Bible studies, go to church, which are very good things, but when you spend every day going to bed at 1:00, 1:30 because you were doing homework, waking up at 7:30 because you have more homework to do before class starts, and then going to chapel, and then going to class until 3:00 or 4:00, and then going to the engineering building and doing homework until 1:30, it's hard to find some personal time for you and for your faith to grow" [Dale, Focus Group \#10, 00:15:00]

Dale describes expectations that conflict almost directly with each other, as he experiences some personal and spiritual stagnation due to his academic dedication. His academic expectations (classes and homework) compete directly with vital extra-curricular expectations (personal and spiritual growth, as well as community involvement) which originate from his institution's culture. At some level, we recognize the issue of time but more prominently the student talks about developing facets of identity that each require extensive personal investment. His current investment in academics damages his ability to develop as a Christian because progress in one area hampers progress in the other. We see that even though both identity facets are salient and positive on their own, Dale experiences a significant struggle when attempting to satisfy both demands simultaneously. Consequently, he might perceive that a thorough fulfilment of his academic expectations might detract from his community involvement and spiritual growth while the latter would benefit from a decrease in academic obligations. Thus, the expectations are not inherently conflicting, but would be internalized as conflicting due to the investment required for each, escalated by differences in the facets of identity each one emphasizes i.e., professional development and personal development. This pattern of experience was conspicuous across the data, by similar sentiments of essentially developing one aspect of identity at the expense of other positive elements. 
In addition to conflicting facets of identity, students also experience dissonance with regards to academic talent and effort. The following example provides an illustration of this second strand of conflicting expectations. Tehzlyn, a second-year mechanical engineering major describes her experiences with sharing her major with non-engineers who assume that inherent intelligence is a definitional aspect of engineering. This expectation from entities outside the major is extremely common, a fact pointed out by the student herself ("I feel like you guys too"). However, she expresses a conflict between those outside expectations with engineering expectations of hard work and dedication as well as an inclination toward the latter.

"[...] I always say mechanical engineering, and I feel you guys too, a different person would be like oh, he must be so smart, and I don't really know how to respond to that, because I'm not the best at math. I feel like in engineering you've just got to work hard and train your mind to think a certain way, but I know that - I don't know. It doesn't mean that we're all intelligent and super smart." [Tehzlyn, Focus Group \#4, 00:57:34]

Tehzlyn talks about the expectation to be smart simply due to her status as an engineering student. Across the data, "smartness" emerged as a salient marker of engineering students' identity in their transition from high school, which is eventually lost as they struggle to meet the academic requirements of the engineering program. Their struggle is more due to dramatic increase in rigor and expectations for performance which may require some adjustment, than an ineptitude for engineering coursework. Students might also achieve excellent academic evaluations without experiencing a sense of academic competence. As a result, their transition from high school is essentially followed by a transition from their "smart" identity to embracing expectations of hard work within the department. Therefore, when entities outside the major introduce expectations about "smartness," these expectations conflict with the hard-working identity the students have constructed. They experience severe dissonance as they are faced with assumptions they no longer identify with, as much as they would like to relate. This dissonance is partially aided by a common sentiment identified in the data that being intelligent means not having to work hard and working hard means that intelligence alone is not enough. Tehzlyn expresses this idea in her statements ("it doesn't mean that we're all intelligent and super smart") by essentially implying that "smartness" and hard work are mutually exclusive. She suggests that having to work hard and not being naturally proficient at math spontaneously suggests some inadequacy in intelligence. Across the data, outside expectations regarding "smartness" and engineering expectations about hard work are discussed in a similar manner which presents them as conflicting expectations, with emphasis on one aspect automatically decreasing emphasis on the other, due to the implied mutual exclusivity. The result of this idea is essentially a choice of one expectation to fulfill when students are faced with both expectations about hard work and expectations about "smartness".

These examples demonstrate a mechanism through which expectations from different sources are set against each other through dissonance and forced choice, even though the expectations are rarely inherently conflicting. More specifically, "being smart" and "working hard" are not mutually exclusive but are culturally constructed as binary choices. However, the data presents salient and prevalent expressions of conflict when certain expectations clash, suggesting the prominence of conflicting expectations as a vehicle for students' perceptions of engineering expectations. 


\section{Triangulating Expectations}

Triangulating expectations constitute the third mechanism through which expectations interact, and they are characterized by similar expectations from multiple sources which encourage the same behavior. It is different from the compounding mechanism in that the subsequent stress overload is due to an exaggerated emphasis on a particular expectation rather than the influence of multiple expectations. The perception of one expectation from multiple sources serves as a steady reminder of its importance in engineering, which can be extremely stress-inducing because it creates the appearance that a sole expectation is the primary authenticator in engineering. In fact, a single expectation can even be perceived as the defining factor for the student's success in engineering, which diminishes the significance of other expectations in comparison. Through this gradual process, external sources of expectations can influence students' perception and valuing of an individual expectation - and indeed other expectationsregardless of their own preferences and values.

The following quotes illustrate how a single expectation can appear ubiquitous when reinforced from multiple sources. The students describe how the consistent input from multiple entities regarding the extra-curricular expectation for students to obtain internships can establish internships as a fundamental measure of engineering success and achievement.

"For electrical and computer, the expectation is to get an internship, you're expected to get an internship after your junior year [...] if you don't get an internship you aren't really going to get a good job. And so [professor] is like, oh, let's -- every time you go to talk to him about anything he's like okay, so let's talk about internships" [Vivian, Focus Group \#6, 00:25:26]

"I always get those e-mails from like [internship coordinator] about the different internships" [Kia, Focus Group \#3, 01:02:20]

"[...] when I look at all these people around me I'm like wow, that's so cool, my friend's doing this, doing that, I have to do something. I need to do that. I need to get the internship." [Elsa, Focus Group \#5, 00:17:00]

Each statement describes one source of the same expectation, with "professor" and "internship coordinator" being both superiors and "people around me" being peers. Since the expectation itself is of the extracurricular type, a variety of sources contribute to this mechanism. We recognize that the statements represent the perspectives of different students, but they also portray common experiences which students encounter and have the potential to encounter regularly. In fact, all three students attend the same institution and imply that these experiences are not at all unique to them: Vivian states, "[...] you're expected to get an internship [...]", Kia describes mass emails which nearly every student receives, and Elsa mentions "all these people around me [are getting internships]", an observation any student could make. Since these expectations are echoed throughout the engineering environment, they become definitional elements of engineering requirements, as expressed by Vivian ("if you don't get an internship you aren't really going to get a good job"). Across the data, internships are viewed as important for experience, but the triangulation can cause an overload which is extremely stress-inducing for students. Other expectations have similar effects on students' perceptions, as they are echoed 
throughout the social and cultural environment. Prominent examples are expectations about grades, hard work, and campus involvement. Such expectations are internalized more intensely because their ubiquity would suggest a fundamental significance for students' engineering identity. In this way, certain engineering expectations gradually rise in prominence from a personal and professional perspective which changes how they — and other expectations - are perceived.

\section{Discussion}

The findings provide an overview of the sources of expectations for engineering students, some of which mirror prior research in engineering education [e.g. 20] or other educational contexts [e.g. 6, 19].

Beyond this overview, the codes for the sources of expectations also illustrate the varied complexity of a network of expectations our students experience. In other words, this landscape of expectations is dynamic, varied, and interconnected. For example, the findings show that students perceive related expectations from within the engineering context (e.g. peer, superiors) and from outside (e.g. non-engineering friends, parents). The internal sources are often steeped in the disciplinary culture $[46,47]$ and provide specifically constructed versions of what those expectations mean. The outside sources of expectations do not have the same connotations of disciplinary culture and might in some ways diverge from internal expectations, but share central elements. For example, within the engineering environment participants described how expectations around grades are informed by notions of rigor and hard work [58,59] without necessarily associating top grades with success. For outside sources, parents' expectations might center more on high grades and understand success through notions of 'smartness' that they associated with engineering as a field. This interplay and connection of sources and signals for expectations suggest a robust and compelling system of expectations. Common cultural threads affirm expectations and place them in context of disciplinary characteristics and narratives. The variations and tensions at the level of individual signals that students interpret, creates a vibrant engagement of participants in these processes of social construction.

This dynamically interconnected nature of the system of expectations also emerged as a significant factor in how students experienced and internalized those expectations. That is, students' self-assessments were not based on individual sources, but were informed by being exposed to the systemic functioning of a landscape of expectations. On the level of the public discourse around engineering education, Sochacka et al. [59] describe a similar pattern of the discursive construction of definitions of engineering in dynamic autopoetic systems [60-62]. More specifically, definitional narratives about engineering gain significance through the variations and, sometimes, tensions between the ways in which those definitions are articulated. The patterns around compounding, triangulating, and conflicting interactions between sources of expectations further unpack this systemic functioning. Compounding speaks to the scope or magnitude of expectations that students perceived in the various aspects of their educational environment. The analysis of the data showed how the subjective perception of the aggregate of all expectations can leave students feeling overwhelmed and discouraged. Triangulation showed how variation and confirmation of expectations from different sources can amplify the weight and importance of those aspects in the subjective perception of an individual student. The quotes illustrated the emotional significance of students perceiving that they don't meet those amplified 
expectations. Conflicting expectations similarly amplify the impact of expectations, particularly when the conflicting signals pit significant aspects of students' lives against the socially constructed ways of being an engineering student.

The above insights about the sources of students' experiences with expectations have implications for engineering educators and point to future empirical avenues for engineering education researchers.

As engineering educators, when we communicate expectations or standards of academic performance to students, we are part of and contribute to an ecosystem of pressures for students. Recognizing the systemic effects of the signals we send is challenging in an academic environment where courses are often separated with limited opportunities for instructors to get a sense of other pressures students experience. At another level, the culturally informed facets of the ways in which expectations are experienced by students provide an opportunity for educators to consider that when we communicate expectations about our course, we are also telling students something about engineering. More specifically, we might inadvertently reinforce cultural notions of rigor [58] and hard work that not only shape the experience of students in our programs but also their beliefs of what engineering is, what makes a good engineer, who should be an engineer, and, ultimately, who shouldn't. In other words, we might strive to find ways to communicate performance standards without stating or implying culturally definitional facets of engineering that might be problematic for students' experiences or exclusionary for some groups. If we realize that communicating necessary standards in a specific course is situated in a larger cultural construction of expectations, we might consider balancing these signals with other messages in the broader context. For example, an instructor might communicate performance expectations clearly in a course but also discuss their commitment to supporting students and make room for emotionally the challenging experiences students may have.

For engineering education researchers, the findings and discussion offered here point to the experiential and affective significance of expectations for individual students. The focus of this study was on the collective construction of expectations, however, participants' accounts suggested profound internal emotional experiences. The focus group format of gathering data was not designed or suitable to elicit more nuanced accounts of internal experience. Further work theoretically framed around shame is beginning to explore the internal individual experience of students to better understand the depth and scope of emotional impacts on students $[17,18]$. The facets of disciplinary culture that became visible in the analysis here suggests opportunities to further investigate ways in which perceptions or definitional narratives about engineering are shaped by the social construction of expectations. We showed that these processes can conflate academic performance standards with cultural expectations of what it means to be an engineering student or a professional engineer. A deeper study of these dynamics could help us understand how expectations, their social construction, and individual shame experiences could lie at the heart of professional formation and socialization processes. 


\section{References:}

[1] D. E. Chubin, G. S. May, and E. L. Babco, "Diversifying the engineering workforce," Journal of Engineering Education, vol. 94, no. 1, pp. 73-86, 2005.

[2] C. S. G. Davis and C. J. Finelli, "Diversity and retention in engineering," New Directions for Teaching and Learning, vol. 2007, no. 111, pp. 63-71, 2007, doi: 10.1002/tl.287.

[3] L. L. Leslie, G. T. McClure, and R. L. Oaxaca, "Women and Minorities in Science and Engineering," The Journal of Higher Education, vol. 69, no. 3, pp. 239-276, 1998, doi: 10.1080/00221546.1998.11775134.

[4] G. S. May and D. E. Chubin, "A Retrospective on Undergraduate Engineering Success for Underrepresented Minority Students," vol. 92, no. 1, pp. 27-39, 2003, doi: 10.1002/j.2168-9830.2003.tb00735.x.

[5] A. N. Furry and S. R. Sy, "The influence of perceived parental expectations and pressures on women's academic achievement during the first year of college," Journal of The FirstYear Experience \& Students in Transition, vol. 27, no. 1, pp. 49-67, 2015.

[6] A. K. Sommerfeld, "Education as a collective accomplishment: how personal, peer, and parent expectations interact to promote degree attainment," Social Psychology of Education, vol. 19, no. 2, pp. 345-365, 2016.

[7] J. C. McIntyre, J. Worsley, R. Corcoran, P. Harrison Woods, and R. P. Bentall, "Academic and non-academic predictors of student psychological distress: the role of social identity and loneliness," Journal of Mental Health, Article vol. 27, no. 3, pp. 230239, 2018, doi: 10.1080/09638237.2018.1437608.

[8] K. J. Reddy, M. S. Karishmarajanmenon, and Anjanathattil, "Academic Stress and its Sources among University Students," Biomedical and Pharmacology Journal, Article vol. 11, 2018.

[9] K. Hull et al., "Student Anxiety and Evaluation," Collected Essays on Learning and Teaching, vol. 12, pp. 23-35, 2019.

[10] B. D. Jones, C. Ruff, and M. C. Paretti, "The Impact of Engineering Identification and Stereotypes on Undergraduate Women's Achievement and Persistence in Engineering," Social Psychology of Education: An International Journal, vol. 16, no. 3, pp. 471-493, 2013.

[11] J. Valerio, Attrition in Science, Technology, Engineering, and Mathematics (STEM) Education: Data and Analysis (Education in a Competitive and Globalizing World). New York: Nova Science Publishers, Inc, 2014.

[12] T. Conefrey, "Sexual Discrimination and Women's Retention Rates in Science and Engineering Programs," Feminist Teacher, vol. 13, no. 3, pp. 170-192, 2001.

[13] E. O. McGee and D. B. Martin, "'You would not believe what I have to go through to prove my intellectual value!" Stereotype management among academically successful Black mathematics and engineering students," American Educational Research Journal, vol. 48, no. 6, pp. 1347-1389, 2011, doi: doi: 10.3102/0002831211423972.

[14] B. J. Lameres, M. S. Burns, D. B. Thoman, and J. L. Smith, "The Role of Prosocial Goal Congruity on Student Motivation in Electrical Engineering," IEEE Transactions on Education, Education, IEEE Transactions on, IEEE Trans. Educ., Periodical vol. 62, no. 4, pp. 256-263, 2019, doi: 10.1109/TE.2019.2897265.

[15] F. Sagebiel and J. Dahmen, "Masculinities in Organizational Cultures in Engineering Education in Europe: Results of the European Union Project WomEng," European Journal of Engineering Education, vol. 31, no. 1, pp. 5-14, 2006. 
[16] J. Huff, N. W. Sochacka, J. Walther, S. Miller, and J. Sullins, "Examining the Experience of Shame as a Key Mechanism for Socialization in Engineering Education," in Society for Personality and Social Psychology Annual Convention, Altanta, Georgia, 2018/03/01/ 2018.

[17] J. L. Huff et al., "Shame in Engineering: Unpacking the Socio-Psychological Emotional Construct in the Context of Professional Formation," in American Society for Engineering Education Annual Conference, Salt Lake City, Utah, 06/23 2018: ASEE Conferences.

[18] J. L. Huff et al., "Exploring shame in engineering education," in Frontiers in Education Conference (FIE), 2016: IEEE, pp. 1-4.

[19] R. P. Ang and V. S. Huan, "Academic Expectations Stress Inventory:Development, Factor Analysis, Reliability, and Validity," Educational and Psychological Measurement, vol. 66, no. 3, pp. 522-539, 2006, doi: 10.1177/0013164405282461.

[20] G. Hackett, N. E. Betz, J. M. Casas, and I. A. Rocha-Singh, "Gender, ethnicity, and social cognitive factors predicting the academic achievement of students in engineering," Journal of counseling Psychology, vol. 39, no. 4, p. 527, 1992.

[21] W. Schafer, Stress management for wellness. Harcourt Brace College Publishers, 1996.

[22] C. W. Struthers, R. P. Perry, and V. H. Menec, "An Examination of the Relationship Among Academic Stress, Coping, Motivation, and Performance in College," Research in Higher Education, vol. 41, no. 5, pp. 581-592, 2000, doi: 10.1023/A:1007094931292.

[23] J. Hunt and D. Eisenberg, "Mental health problems and help-seeking behavior among college students," Journal of adolescent health, vol. 46, no. 1, pp. 3-10, 2010.

[24] K. De Castella, D. Byrne, and M. Covington, "Unmotivated or motivated to fail? A crosscultural study of achievement motivation, fear of failure, and student disengagement," Journal of Educational Psychology, vol. 105, no. 3, p. 861, 2013.

[25] G. Bottesi, A. Martignon, S. Cerea, and M. Ghisi, "Worry and associated cognitive features in Italian university students: Does gender make a difference?," Personality and Individual Differences, vol. 126, pp. 38-43, 2018, doi: 10.1016/j.paid.2018.01.016.

[26] R. N. Carleton, M. A. P. J. Norton, and G. J. G. Asmundson, "Fearing the unknown: A short version of the Intolerance of Uncertainty Scale," Journal of Anxiety Disorders, Article vol. 21, no. 1, pp. 105-117, 2007, doi: 10.1016/j.janxdis.2006.03.014.

[27] D. Bédard, C. Lison, D. Dalle, D. Côté, and N. Boutin, "Problem-based and Project-based Learning in Engineering and Medicine: Determinants of Students' Engagement and Persistance," Interdisciplinary Journal of Problem-based Learning, Article vol. 6, no. 2, pp. 7-30, 2012, doi: 10.7771/1541-5015.1355.

[28] N. C. Hall and A. Sverdlik, "Encouraging Realistic Expectations in STEM Students: Paradoxical Effects of a Motivational Intervention," (in eng), Front Psychol, vol. 7, pp. 1109-1109, 2016, doi: 10.3389/fpsyg.2016.01109.

[29] R. M. Webb, D. Lubinski, and C. P. Benbow, "Mathematically facile adolescents with math-science aspirations: New perspectives on their educational and vocational development," Journal of Educational Psychology, vol. 94, no. 4, pp. 785-794, 2002, doi: 10.1037/0022-0663.94.4.785.

[30] N. Bayram and N. Bilgel, "The prevalence and socio-demographic correlations of depression, anxiety and stress among a group of university students," Social Psychiatry \& Psychiatric Epidemiology, Article vol. 43, no. 8, pp. 667-672, 2008, doi: 10.1007/s00127-008-0345-x. 
[31] K. Phillips, "Non-traditional minority students," Research Starters: Education (Online), 2015.

[32] S. McClain, S. T. Beasley, B. Jones, O. Awosogba, S. Jackson, and K. Cokley, "An examination of the impact of racial and ethnic identity, impostor feelings, and minority status stress on the mental health of Black college students," Journal of Multicultural Counseling and Development, vol. 44, no. 2, pp. 101-117, 2016.

[33] A. M. Santiago and M. K. Einarson, "Background characteristics as predictors of academic self-confidence and academic self-efficacy among graduate science and engineering students," Research in higher education, vol. 39, no. 2, pp. 163-198, 1998.

[34] K. Diehl, C. Jansen, K. Ishchanova, and J. Hilger-Kolb, "Loneliness at universities: determinants of emotional and social loneliness among students," International journal of environmental research and public health, vol. 15, no. 9, p. 1865, 2018.

[35] L. M. Heinrich and E. Gullone, "The clinical significance of loneliness: A literature review," Clinical Psychology Review, vol. 26, no. 6, pp. 695-718, 2006, doi: 10.1016/j.cpr.2006.04.002.

[36] D. S. Bahmani, P. Faraji, R. Faraji, U. E. Lang, E. Holsboer-Trachsler, and S. Brand, "Is emotional functioning related to academic achievement among university students? Results from a cross-sectional Iranian sample," Revista Brasileira de Psiquiatria, vol. 40, no. 3, pp. 290-295, 2018, doi: 10.1590/1516-4446-2017-2434.

[37] A. Ramirez-Arellano, E. Acosta-Gonzaga, J. Bory-Reyes, and L. M. Hernández-Simón, "Factors affecting student learning performance: A causal model in higher blended education," Journal of Computer Assisted Learning, vol. 34, no. 6, pp. 807-815, 2018, doi: 10.1111/jcal.12289.

[38] N. R. Jackson, "Comparing active and didactic pedagogies in electronic engineering," Electronic Thesis or Dissertation, Staffordshire University, 2018.

[39] R. M. Vasconcelos and L. S. Almeida, "Academic Expectations for Engineering Freshmen: Gender Differences," in 2018 IEEE International Conference on Teaching, Assessment, and Learning for Engineering (TALE), 2018: IEEE, pp. 716-719.

[40] K. Stansbury, "The Relationship of the Supportiveness of the Academic Environment to the Self-Confidence and Assertiveness in Academic Work for Men and Women Graduate Students in Science and Engineering," presented at the Annual Meeting of the American Educational Research Association, San Fransisco, CA, April 16-20, 1986.

[41] C. M. Vogt, D. Hocevar, and L. S. Hagedorn, "A social cognitive construct validation: Determining women's and men's success in engineering programs," The Journal of higher education, vol. 78, no. 3, pp. 337-364, 2007.

[42] K. M. Schilling and K. L. Schilling, "Increasing expectations for student effort," About Campus, vol. 4, no. 2, pp. 4-10, 1999.

[43] S. Zoghi, "Engineering Economics and Its Role in The Engineering Curricula," Proceedings of the ASEE Annual Conference \& Exposition, 2015.

[44] C. E. Foor, S. E. Walden, and D. A. Trytten, "'I Wish that I Belonged More in this Whole Engineering Group:" Achieving Individual Diversity," Journal of Engineering Education, vol. 96, no. 2, p. 103, 2007.

[45] Committee on Public Understanding of Engineering Messages, Changing the Conversation: Messages for Improving Public Understanding of Engineering. Washington, DC: National Academy of Engineering, 2008. 
[46] E. Godfrey and L. Parker, "Mapping the cultural landscape in engineering education," Journal of Engineering Education, vol. 99, no. 1, pp. 5-22, 2010.

[47] A. L. Pawley, "Universalized narratives: Patterns in how faculty members define "engineering"," Journal of Engineering Education, vol. 98, no. 4, pp. 309-319, 2009.

[48] W. C. Lee, "Pipelines, pathways, and ecosystems: An argument for participation paradigms," Journal of Engineering Education, vol. 108, no. 1, pp. 8-12, 2019, doi: 10.1002/jee.20241.

[49] R. M. Emerson, R. I. Fretz, and L. L. Shaw, Writing Ethnographic Fieldnotes. University of Chicago Press, 1995.

[50] M. D. LeCompte, J. P. Goetz, and R. Tesch, Ethnography and Qualitative Design in Educational Research, 2nd Edition. Emerald Group Publishing Limited, 1993.

[51] R. S. Barbour, "Doing focus groups," in The SAGE qualitative research kit, U. Flick Ed. London: SAGE, 2007.

[52] D. L. Morgan, Focus groups as qualitative research. Newbury Park, CA: SAGE, 1988.

[53] P. Bazeley, Qualitative data analysis with NVivo, 2nd ed. Los Angeles; London: SAGE, 2007.

[54] J. Walther et al., "Qualitative Research Quality: A Collaborative Inquiry Across Multiple Methodological Perspectives," Journal of Engineering Education, vol. 106, no. 3, pp. 398-430, 2017, doi: 10.1002/jee.20170.

[55] A. L. Pawley, "“Asking questions, we walk": How should engineering education address equity, the climate crisis, and its own moral infrastructure?," Journal of Engineering Education, vol. 108, no. 4, pp. 447-452, 2019.

[56] L. Richards, Handling qualitative data: a practical guide. London; Thousand Oaks, CA: SAGE Publications, 2005.

[57] C. Geertz, The interpretation of cultures: selected essays. New York: Basic Books, 1973.

[58] D. Riley, "Rigor/Us: Building Boundaries and Disciplining Diversity with Standards of Merit," Engineering Studies, vol. 9, no. 3, pp. 249-265, 2017, doi: 10.1080/19378629.2017.1408631.

[59] N. W. Sochacka, J. Walther, J. Wilson, and M. Brewer, "Stories 'Told' about Engineering in the Media: Implications for attracting diverse groups to the profession," in Frontiers in Engineering Education Conference, Madrid, Spain, 2014.

[60] J. Bednarz, "Autopoiesis: The organizational closure of social systems," Systems Research, vol. 5, no. 1, pp. 57-64, 1988, doi: 10.1002/sres.3850050107.

[61] S. Blaschke, Structures and Dynamics of Autopoietic Organizations: Theory and Simulation. Gabler, 2008.

[62] F. Geyer, "Autopoiesis and Social Systems," International Journal of General Systems, vol. 21, no. 2, pp. 175-183, 1992, doi: 10.1080/03081079208945068. 